\title{
Energetic model of metal hardening
}

\author{
O.N. Ignatova ${ }^{\mathrm{a}}$ and V.A. Raevsky \\ FSUE “RFNC - VNIIEF”, Sarov, Russia
}

\begin{abstract}
Based on Bailey hypothesis on the link between strain hardening and elastic lattice defect energy this paper suggests a shear strength energetic model that takes into consideration plastic strain intensity and rate as well as softening related to temperature annealing and dislocation annihilation. Metal strain hardening was demonstrated to be determined only by elastic strain energy related to the energy of accumulated defects. It is anticipated that accumulation of the elastic energy of defects is governed by plastic work. The suggested model has a reasonable agreement with the available experimental data for copper up to $P=70 \mathrm{GPa}$, for aluminum up to $P=10 \mathrm{GPa}$ and for tantalum up to $P=20 \mathrm{GPa}$.
\end{abstract}

\section{Introduction}

The effect of strain mode on metal structure and mechanical properties has been studied for several decades. In [1] and [2] it has been found that the metal strength increases under wave loading, and this is explained by fast growth of dislocation and twins density behind the shock front. Sophisticated study of the microstructure change in [3-5] has been performed using an electron microscope and $\mathrm{X}$-ray diffractometer. These and others studies demonstrate that the metal hardening under strain relates to structural changes, exactly to dislocation density increase [6-10] and grain size decrease $[6,11,12]$ and under high strain rate it relates to microtwinnig [7-10]. Thus, it enables one to make a general pattern of defect formation after high-speed loading in solids. The basic result of the research is establishing the relationship between final mechanical properties and the density of the formed defects [13-15].

In ref. [16] the authors in calorimetric measurements have determined the stored energy of defects $\left(W^{E}\right)$ and calculated the shear strength after the shock loading based on Bailey hypothesis [17]. Computations described experiments for copper and nickel reasonably well. However, [16] does not provide relationships for calculating elastic energy through plastic strain work, and does not take into account temperature annealing at shock loading that can significantly change the final metal state.

The basic goal of this study is constructing relationships between the metal yield strength and plastic work that has been going on under strain both at static strain and shock loading. Therewith annealing at increased temperature is taken into consideration.

\section{Metal hardening under strain}

For annealed pure metals $(\mathrm{Cu}, \mathrm{Al}$, etc. $[10,18,19])$ usually having fcc lattice the strain hardening can be reasonably high (5-7 times). For some metals the hardening value depends not only on plastic strain, but also on its rate. Thus, for example pure copper after shock loading of $>30 \mathrm{GPa}$ intensity at strain rate of $\dot{\varepsilon}>10^{7} \mathrm{c}^{-1}$ is hardened a factor of 5-6 up to the value $\sigma_{0.2} \sim 300-400 \mathrm{MPa}$ [18].

\footnotetext{
a e-mail: root@gdd.vniief.ru
}

This is an Open Access article distributed under the terms of the Creative Commons Attribution-Noncommercial License 3.0, which permits unrestricted use, distribution, and reproduction in any noncommercial medium, provided the original work is properly cited. 
This effect relates to intensive generation of dislocations and twins at high-speed shock strain. It should be noted here that 5-6-times hardening can be reached also at low strain (strain rate of $\dot{\varepsilon} \sim 10^{-3} \mathrm{~s}^{-1}$ ), but the strain intensity here will be higher than $100 \%$.

However, in intensive shock waves in addition to high strain rate also high temperatures are implemented, at which defects can be annealed and strength properties can be "returned" back to their initial state. It is evident that for aluminum and copper having fcc lattice metal hardening goes faster after shock loading. It is described by increased conventional yield strength as compared to similar behavior at slow quasi-static loading. Additional hardening occurs as a result of large quantity of dislocations and microtwins increasing boundaries that impede dislocation movements. For tantalum having bcc lattice this effect was not evidenced within the range of investigation $P<20 \mathrm{GPa}$. Thus, description of metal hardening should take into consideration strain mode: amount of strain and strain rate. Construction of such model is a challenge. However, its simplified solution is possible on the basis of Bailey energetical theory [17]. According to [17] hardening is conditioned by integrated energy of crystal defects $W^{E}$ - dislocations, grain boundaries, twins, etc. As investigations show each metal has its limiting hardening which is similar for various strain modes. Consequently, there is the fault energy density limit $W_{\max }^{E}$. At increased temperature the value $W_{\max }^{E}$ shows a decrease as a result of annealing.

\section{Metal hardening energetic model}

According to Bailey [17] and Grace [16] we also assume that metal strain hardening is determined only by the elastic energy $W^{E}$ that is connected with the accumulated energy in deformation.

A relaxation strength model taking into consideration the increase of stress intensity with the strain rate growth in shock waves:

$$
\dot{Y}_{d}=3 G \dot{\varepsilon}_{i}-\frac{Y_{d}-Y_{S}}{\tau},
$$

where $Y_{d}-$ is an effective yield strength at the given time, $Y_{S}-$ is a stationery yield strength, being implemented at the given state $(P, T)$ of material at $\dot{\varepsilon}_{i}=0 ; \dot{\varepsilon}_{i}$ - is a strain rate; $G-$ is a shear modulus, $\tau$ - elastic stress relaxation time $\left(\tau=f\left(\dot{\varepsilon}_{i}, T, G\right)\right)$.

We set the stationary yield strength $Y_{S}$ as:

$$
Y_{S}=Y_{0} \cdot\left(1+(\omega)^{1 / 2}\right) \cdot \frac{G}{G_{0}},
$$

where $G_{0}, G$ - are the shear modules in the initial and current states, $Y_{0}$ - is the initial yield strength determined from static experiments.

In the first approximation the $\omega$-function can be represented by the following relaxation equation:

$$
\dot{\omega}(t)=\frac{\dot{A}^{P}}{E_{0}} \cdot\left(\omega_{\max }-\omega\right)-\frac{\omega-\omega_{a}(\bar{T})}{\tau_{a}} \cdot \Theta,
$$

where $\omega_{a}(\bar{T})$ - is temperature-dependent hardening, $\bar{T}=T / T_{m}, T, T_{m}$ - are current temperature and melting temperature in the given stress-strain state, $\tau_{a}-$ is the temperature "return" time, $\tau_{0}-$ is a parameter, $\Theta-$ is Heaviside function.

In the first approximation the temperature dependent relaxation time $\tau_{a}$ and hardening time can be represented as:

$$
\begin{gathered}
\tau_{a}=\tau_{0} \cdot e^{\frac{\bar{T}_{0}}{T}}, \\
\omega_{a}(T)=\omega_{\max } \cdot\left(1-\left(\frac{\bar{T}}{\bar{T}_{a n}}\right)^{n 2}\right), \quad \bar{T} \leq \bar{T}_{a n} \\
\omega_{a}(T)=0 \quad \bar{T}>\bar{T}_{a n}
\end{gathered}
$$

where $\tau_{0}, \bar{T}_{0}, n_{2}$ - are constants, $\bar{T}_{a n}=\frac{T_{a n}}{T_{m}}, T_{a n}-$ is annealing temperature equal for the majority of metals to $(0.35-0.45) \cdot T_{m}$. 


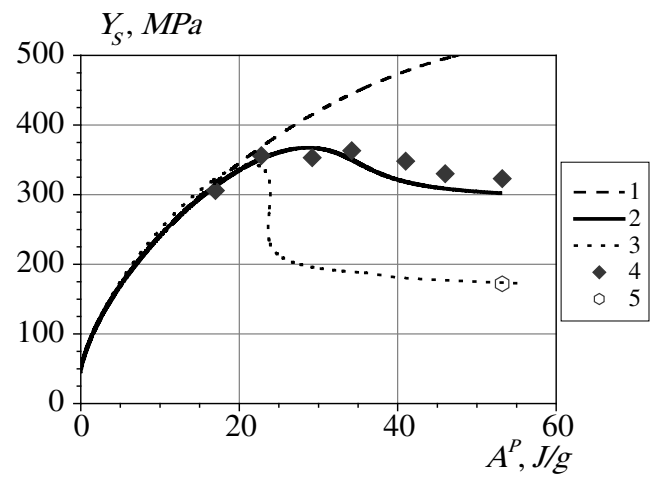

Fig. 1. The relationship between calculated and experimental curves of the yield strength and the calculated copper plastic deformation work under shock strain up to the pressure $P=70 \mathrm{GPa}$, with various action times $t_{S W}<1 \mu \mathrm{s}$ and $t_{S W} \gtrsim 2 \mu \mathrm{s}: 1$ - calculation according to (3) without including temperature relaxation; 2 - calculation according to (3) without temperature relaxation; 3 - calculation according to (3) including temperature relaxation; 4 - experiment at $t_{S W}<1 \mu \mathrm{s} ; 5$ - experiment at $t_{S W} \gtrsim 2 \mu \mathrm{s}$.

\section{Comparison with the experiment}

Using relationships (1)-(6) the final strength of macrocrystalline copper was calculated after shock loading up to pressures of $\sim 70 \mathrm{GPa}$. At low deformation copper is known to be hardened from $\sim 55$ to $\sim 500 \mathrm{MPa}$, i.e., a factor of 10 , and annealing takes place at $T_{a n} \sim(0.3--0.5) \cdot T_{m}$. In calculations the following values were used: $\omega_{\max }=9.1^{2}=82.8$ and $\bar{T}_{a n}=0.42$. The thermal relaxation time $\tau_{a}$ can be evaluated from experiments investigating the shock time impact $\left(t_{S W}\right)$ on the final strength. Thus, at $P=65-70 \mathrm{GPa}$ and $t_{S W}<1 \mu \mathrm{s}, Y_{S}=323 \mathrm{MPa}$, when the time $t_{S} \gtrsim 2 \mu \mathrm{s}, Y_{S}=172 \mathrm{MPa}$. In Eq. (4) $\tau_{0}=2 \cdot 10^{-6} \mathrm{~s}$.

Figure 1 provides the calculation data using the energetic model (1)-(6) as compared to the experimental data of copper final strength after shock loading up to the pressure $P=70 \mathrm{GPa}$ and with various action times $t_{S W}<1 \mu \mathrm{s}$ and $t_{S W} \gtrsim 2 \mu \mathrm{s}$.

\section{Conclusion}

This paper considers the energetic model of metal hardening. It is assumed that metal strain hardening is determined only by the elastic energy of accumulated defects during deformation. The suggestion is that the defect energy and hardening are determined by deformation plastic work and temperature and do not depend on deformation mode and rate. The relationship between the yield strength and the plastic work has been put forward. The model takes into consideration the hardening related to the accumulated during deformation defects and the annealing as a result of high temperatures implemented in high shock waves. The proposed model has a reasonable agreement with the available experimental data for copper up to $P=70 \mathrm{GPa}$, for aluminum up to $P=10 \mathrm{GPa}$ and for tantalum up to $P=20 \mathrm{GPa}$.

This study is performed with the support of RFFR (Project \# 08-02-00087a) and a scientific school \# NS1307.2008.1.

\section{References}

1. C.S. Smith, Trans. Met. Soc. ATME 212, 574 (1958).

2. G.E. Dieter, Response of Metals to High Velocity Deformation (Interscience Publishers, Ins., New York), vol. 9, pp. 409-445 (1961). 
3. O. Johari and G. Thomas, Acta Met. 12, 1153 (1964).

4. R.L. Nolder and G. Thomas, Acta Met. 12, 227 (1964).

5. R.J. DeAnglis and J.B. Cohen, Deformation Twinning (Cordon and Breach Publishers, New York), vol. 25, pp. 430-464 (1964).

6. R.Z. Valiev, I.V. Alexandrov, Ob'emnye nanostructurnye metallicheskiye materially: polucheniye, structura I svoistva, M.: Academkniga, p. 398 (2007).

7. M.A. Meyers, L.E. Murr, Udarnye volny I yavleniya vysokoskorostnoy deformatzii metallov, M.: Metallurgiya, p.512 (1984).

8. V.A. Rayevskiy, A.M. Podurets, V.G. Ganzhin et al., Twin structures in copper after shock and shockless high-speed deformation (Proceedings of the International Conference IX Chariton readings, Sarov, VNIIEF, p.424, 2007).

9. G.N. Epshtein, Stroyeniye metallov, deformirovannykh vzryvom, Moscow, (1980).

10. T. Swanson, Shock waves and high-speed metal deformation effects. Eds. M.A. Meyers, L.E. Murr. M.: Metallurgiya, p.164 (1984).

11. S.A. Novikov, O.N. Ignatova, E.V. Koshatova et al., Izvestiya Rossiyskoy Akademii Raketnykh I Artilleriyskikh Nauk, No 4(41) (2004).

12. A. Mishra, M. Martin, A.M. Meyers et al., High-strain-rate response of ultra-fine-grained copper. Acta materialia, \# 1 (2008).

13. D.C. Brillhart, R.T. DeAnglis, A.G. Preban, J.B. Cohen and P. Gordon, Trans. Met. Soc. AIME 239, 836 (1967).

14. H. Kressel and N. Brown, J. Appl. Phys. 38, 1618 (1967).

15. F.I. Grace, M.C. Inman and L.E. Murr, Brit. J. Appl. Phys. 1, 1437 (1968).

16. F.I. Grace, Journal of Applied Physics, volume 40, number 6, p.2649 (1969).

17. J.E. Bailey, Phil. Mag. 8, 223 (1963).

18. Yu. V. Bat'kov, I.I. Vedernikova, O.N. Ignatova, A.N. Malyshev, V.A. Rayevskiy et al., Influence of high-rate loading on microstructure and mechanical properties (Proceedings of the International Conference IX Khariton readings, Sarov, VNIIEF, p.435-440, 2007).

19. G.T. Gray III, K.S. Vecchio, Metallurgical and materials transactions A. V. 26A, pp. 1-9 (1995). 